\title{
К ПРОБЛЕМАМ КАЧЕСТВА СОВРЕМЕННОЙ СИСТЕМЫ ВЫСШЕГО ОБРАЗОВАНИЯ В РОССИЙСКОЙ ФЕДЕРАЦИИ
}

\author{
(c) 2021 Агибалова Елена Леонидовна \\ кандидат филологических наук, доцент, кафедра иностранных языков № 3 \\ Российский экономический университет им. Г. В. Плеханова, Россия, Москва \\ E-mail: Agibalova.EL@rea.ru \\ (C) 2021 Чараха Бэр Ада Рут \\ кандидат химических наук, ст.преподаватель, кафедра иностранных языков № 3 \\ Российский экономический университет им. Г. В. Плеханова, Россия, Москва \\ E-mail: Ada.R@rea.ru
}

(c) 2021 Марциновская Виктория Александровна

старший преподаватель, кафедра иностранных языков № 3

Российский экономический университет им. Г. В.Плеханова, Россия, Москва

E-mail:vitam1981@mail.ru

\section{(c) 2021 Циликова Марина Сергеевна}

старший преподаватель, кафедра иностранных языков № 3

Российский экономический университет им. Г. В.Плеханова, Россия, Москва

E-mail:mcilikova@mail.ru

В статье авторов затрагивается многоаспектный вопрос исследования проблемы качества современной системы высшего образования в Российской Федерации. Объектом исследования здесь выступает - система высшего образования в Российской Федерации, а предметом - проблемы качества современной системы высшего образования в Российской Федерации. Теоретическое и методологическое значение исследования заключены в развитии подходов к репрезентации и эффективно обоснованному разрешению проблем высшего образования в Российской Федерации. Практическое и прикладное значение исследования заключены в формировании и развитии направлений повышения качества современной системы высшего образования в Российской Федерации. Отдельно полученные результаты исследования могут быть использованы на практике для решения обширного перечня вопросов, связанных с управлением качества системы высшего образования в Российской Федерации на современном этапе ее развития.

Ключевые слова: Проблема, решение, анализ, качество, современная система, высшее образование, Российская Федерация.

Сложность и многоаспектность сложившейся в настоящее время ситуации на мировой арене активно инициирует всех без исключения субъектов рынка уделять значительное внимание вопросам качества $[3,5]$ процессов и результатов в различных сферах деятельности [1, с. 65].

Так, например, согласно актуальному на начало 2021 года мировому рейтингу анализа глобальных приоритетов, обозначенному компанией Ernst\&Young [7] в рамках действующей программы устойчивого развития, вопросы качества там были расположены на четвертой позиции из первых десяти.

Для Российской Федерации же, учитывая специфику ее текущего развития $[2,6]$, вопросы качества, по уровню их актуальности, в целях локальной корректировки были перемещены на третью позицию.

Динамика позиции качества в рейтинге глобальных приоритетов в Российской Федерации за последние 5 лет (усредненные данные за 2016-2020 годы) приведены на рисунке 1.

Учитывая обозначенные выше моменты, авторским коллективом были детально проработаны вопросы качества (в первую очередь в проекции актуальных проблем) в системе высшего образования в Российской Федерации.

Совокупность выявленных проблем (всего порядка 90 единиц), связанных с качеством современной системы высшего образования в Рос- 


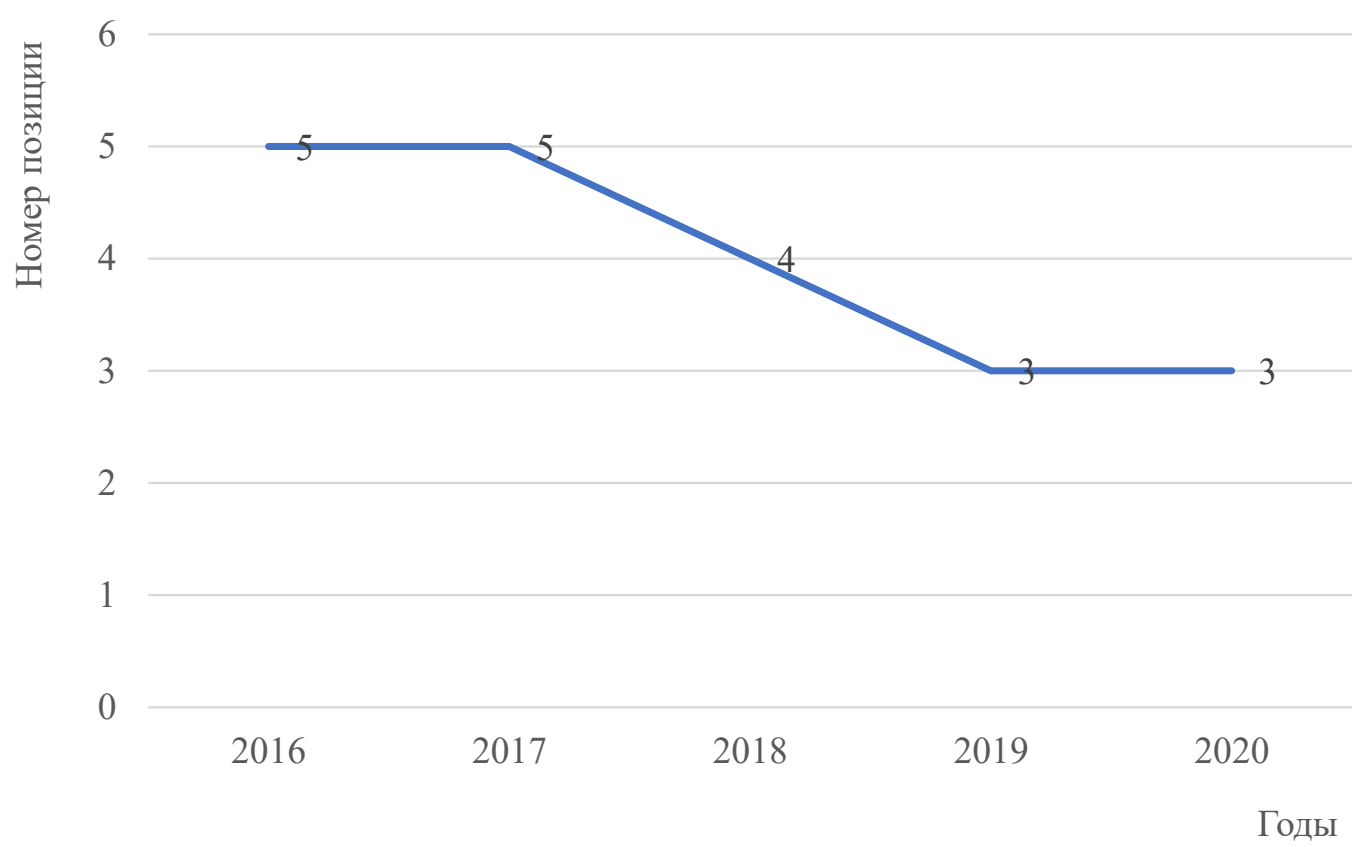

Puc. 1. Динамика позиции качества в рейтинге глобальных приоритетов в Российской Федерации за 2016-2020 годы (усредненные данные)

сийской Федерации, ввиду их многочисленности, целесообразно представить в виде четырех глобальных групп (по данным на начало 2021 года), отображенных на рисунке 2 .

Первая и наибольшая по количеству элементов (доля порядка 35 процентов от совокупного количества) группа проблем объединена под названием «информационные». Сущность проблем, представленных в рамках данной группы, в первую очередь, связана в проекции качества с недостатками всей информационной базы (от точки формирования до распределения и перераспределения информации) современной системы высшего образования в Российской Федерации.
Вторая группа проблем (доля порядка 27 процентов от совокупного количества) объединена сразу под двумя взаимосвязанными терминами «финансы» и «экономика». Сущность проблем, представленных в рамках данной группы, в первую очередь, связана в проекции качества с недостатками финансирования и эффективности использования ресурсов в рамках современной системы высшего образования в Российской Федерации.

Третья группа проблем (доля порядка 21 процента от совокупного количества) объединена сразу под термином «методические». Сущность проблем, представленных в рамках данной группы, в первую очередь, в проекции качества

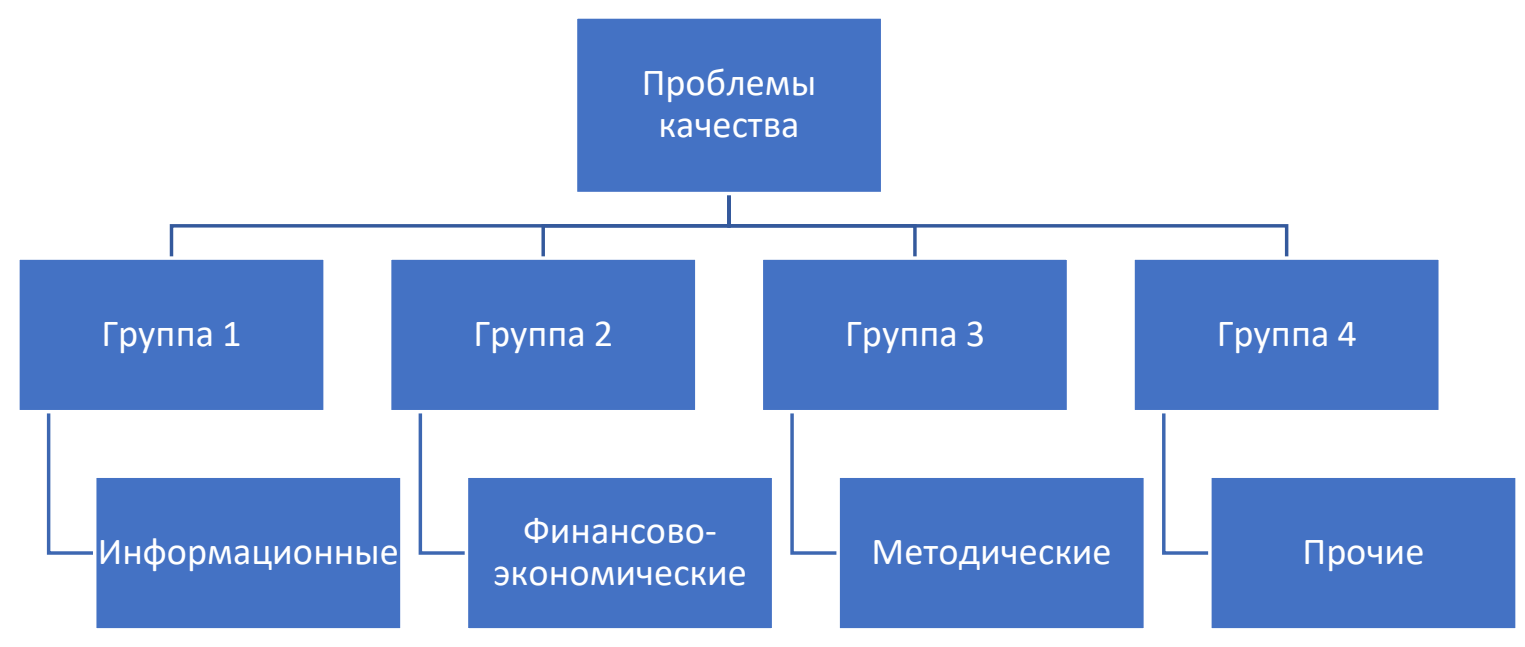

Puc. 2. Группы проблем качества современной системы высшего образования в Российской Федерации (данные на начало 2021 года) 
связана в существующей и применяемой методикой и методологией современной системы высшего образования в Российской Федерации.

Завершающая группа проблем (доля порядка 17 процентов от совокупного количества) объединена сразу под термином «прочие» и является единственной среди данного списка открытой группой, включающей все возможные проблемы, не включенные в три предыдущие группы. Сущность проблем, представленных в рамках данной группы, в проекции связана качества $[4$, c. 14], в том числе с действиями персонала, техническим оснащением, временными проекциями абсолютной и относительной результативности и прочими значимыми элементами.

Относительная значимость четырех групп проблем (от информационных до прочих) по состоянию на начало 2021 года в системе высшего образования в Российской Федерации в интегрированном виде приведена на рисунке 3.

На основе данных рисунка 3, составленного авторами, можно сделать следующие выводы:

- наиболее значимая группа анализируемых проблем современной системы высшего образования в Российской Федерации связана с финансовыми и экономическими аспектами. Значимость данной группы, относительно остальных, на анализируемую дату составляла 38,75 единиц при пиковом возможном значении в 100 единиц;

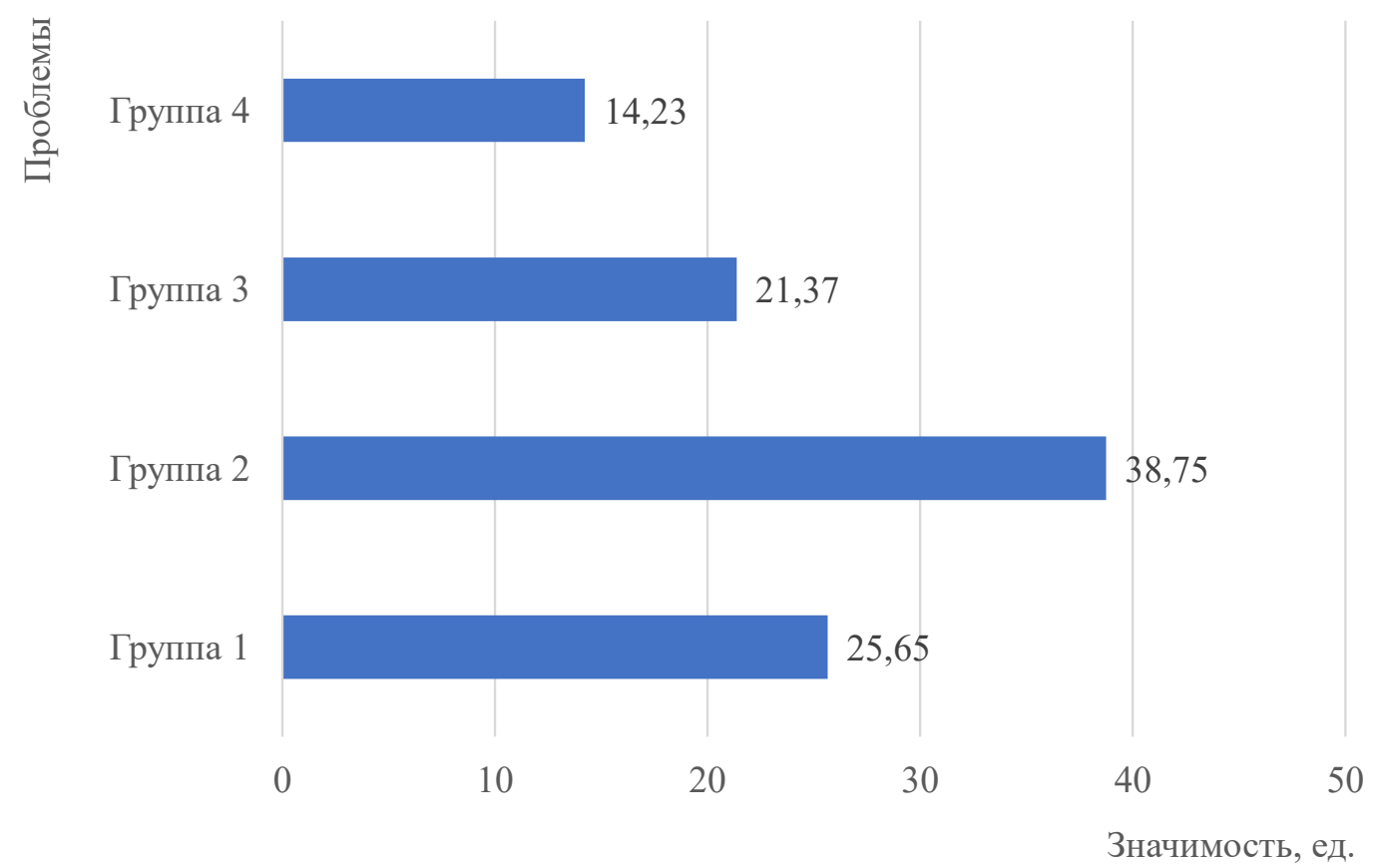

- следующая по значимости группа анализируемых проблем современной системы высшего образования в Российской Федерации связана с информационными аспектами. Значимость данной группы, относительно остальных, на анализируемую дату составляла 25,65 единиц при пиковом возможном значении в 100 единиц;

- чуть меньший уровень значимости (с уровнем на анализируемую дату порядка 21,37 единиц при пиковом возможном значении в 100 единиц) был присущ группе проблем современной системы высшего образования в Российской Федерации, связанной с методическими аспектами;

- завершила рассматриваемый перечень объединенная группа прочих проблем с уровнем значимости на начало 2021 года в 14,23 единицы при пиковом возможном значении в 100 единиц.

Для устранения обозначенного перечня групп проблем предлагается следующая методика, этапы которой приведены ниже:

- выявление локального перечня возможных причин каждой из проблем по группам;

- определение среди локального перечня причин наиболее значимых и их детальное охарактеризование;

- формирование массива инициатив, направленного на нейтрализацию локального перечня наиболее значимых причин в рамках ка-
Значимость, ед.

Рис. 3. Относительная значимость четырех групп проблем по состоянию на начало 2021 года в системе высшего образования в Российской Федерации 
ждой проблемы в первой группе;

- формирование массива инициатив, направленного на нейтрализацию локального перечня наиболее значимых причин в рамках каждой проблемы во второй группе;

- формирование массива инициатив, направленного на нейтрализацию локального перечня наиболее значимых причин в рамках каждой проблемы в третьей группе;

- формирование массива инициатив, направленного на нейтрализацию локального перечня наиболее значимых причин в рамках каждой проблемы в четвертой группе;

- формирование интегрального перечня инициатив, направленного на частичную или полную нейтрализацию локального перечня наиболее значимых причин в рамках всех обозначенных групп.

Согласно данной методике, были разработаны, в том числе, следующие инициативы:

- разработка и внедрение глобальных стандартов единого информационного пространства, определяющего эффективное функционирование современной системы высшего образования в Российской Федерации;

- применение саморегулируемых и настроенных для текущих условий инструментов финансирования и оптимизации распределения инвестиций в современную систему высшего образования в Российской Федерации;

- проведение глобальной и синхронной оптимизации методической и методологической базы функционирования современной системы высшего образования в Российской Федерации;

- использование кадровой реструктуриза- ции во всей совокупности высших учебных заведений в Российской Федерации с акцентом активизации применения онлайн методов обучения в рамках сформированного единого информационного пространства.

Таким образом, можно сделать вывод, что в современных условиях качество системы высшего образования в Российской Федерации находится на недостаточно высоком уровне, ввиду чего сопряжено с наличием целого ряда значимых проблем.

Совокупность данных проблем может быть сгруппирована в четыре самостоятельные группы:

- информационные - связанные в проекции качества с недостатками всей информационной базы;

- финансово-экономические - связанные в проекции качества с недостатками финансирования и эффективности использования ресурсов в рамках современной системы высшего образования в Российской Федерации;

- методические - связанные в проекции качества с существующей и применяемой методикой и методологией современной системы высшего образования в Российской Федерации;

- прочие - связанные в проекции качества, в том числе с действиями персонала, техническим оснащением, временными проекциями абсолютной относительной результативности и т.д.

Для устранения значимых причин данных групп проблем целесообразно реализовать комплекс инициатив, разработанных с применением авторской поэтапной методики.

\section{Библиографический список}

1. Головина И. В., Александрова Т. Я. Качество высшего образования: взгляд изнутри / И. В. Головина, Т. Я. Александрова / Наука и образование: хозяйство и экономика; предпринимательство; право и управление Ростов-на-Дону: Изд-во: «Фонд поддержки образования и науки в Ростовской области (Ростов-на-Дону)», 2020.- № 4.- С. 63-67.

2. Дрондин А. Л. Качество высшего образования: а судьи кто? / А.Л.Дрондин / Бизнес. Образование. Право Волгоград: Изд-во: «Волгоградский институт бизнеса (Волгоград)», 2020. - № 2. - С. 387-391.

3. Николаева Е. А., КузнецоваЮ.А. и другие Инструменты реализации стратегических инициатив высшего учебного заведения в целях повышения качества образовательного процесса / Е. А. Николаева, Ю. А. Кузнецова, Е. Л. Агибалова, Н. В. Каржанова / Экономические науки - Москва: Изд-во: «ООО «24 Принт», 2018.№ 166.- С. 87-90.

4. Тамбовцев В. Л., Рождественская И. А. Менеджмент качества высшего образования: что означает «качество» и что означает «высшее образование»? / В.Л. Тамбовцев, И.А. Рождественская // Управленец - Екатеринбург: Изд-во: «Уральский государственный экономический университет (Екатеринбург)», 2020.- № 2.- С. 2-14.

5. Группа компаний «Деловой профиль» [Электронный ресурс]: аналитические материалы - Официальный сайт группы компаний компании «Деловой профиль», 2021. - Режим доступа: https://delprof.ru/ 
6. Группа компаний «TMF Group» [Электронный ресурс]: аналитические материалы - Официальный сайт группы компаний компании «TMF Group», 2021.- Режим доступа: https:/www.tmf-group.com/ru-ru/

7. Компания «Ernst\&Young» [Электронный ресурс]: аналитические материалы - Официальный сайт компании «Ernst\&Young», 2021.- Режим доступа: https://www.ey.com/ru_ru 